\title{
Co-infections with Plasmodium falciparum, Schistosoma mansoni and intestinal helminths among schoolchildren in endemic areas of northwestern Tanzania
}

\author{
Humphrey D Mazigo*1,7, Rebecca Waihenya², Nicholas JS Lwambo³, Ladislaus L Mnyone4, Aneth M Mahande5,

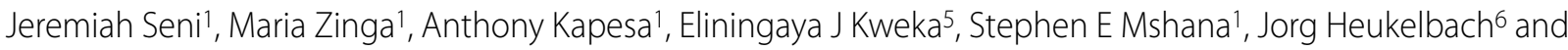 \\ Gerald M Mkoji ${ }^{7}$
}

\begin{abstract}
Background: Malaria, schistosomiasis and intestinal helminth infections are causes of high morbidity in most tropical parts of the world. Even though these infections often co-exist, most studies focus on individual diseases. In the present study, we investigated the prevalence of Plasmodium falciparum-malaria, intestinal schistosomiasis, soiltransmitted helminth infections, and the respective co-infections, among schoolchildren in northwest Tanzania.

Methods: A cross sectional study was conducted among schoolchildren living in villages located close to the shores of Lake Victoria. The Kato Katz technique was employed to screen faecal samples for S. mansoni and soil-transmitted helminth eggs. Giemsa stained thick and thin blood smears were analysed for the presence of malaria parasites.

Results: Of the 400 children included in the study, 218 (54.5\%) were infected with a single parasite species, 116 (29\%) with two or more species, and 66 (16.5\%) had no infection. The prevalences of P. falciparum and S. mansoni were 13.5\% (95\% Cl, 10.2-16.8), and $64.3 \%(95 \% \mathrm{Cl}, 59.6-68.9)$ respectively. Prevalence of hookworm infection was 38\% (95\% Cl, 33.2-42.8). A. lumbricoides and T. trichiura were not detected. Of the children $26.5 \%(95 \% \mathrm{Cl}$, 21.9-30.6) that harbored two parasite species, combination of S. mansoni and hookworm co-infections was the most common (69\%). Prevalence of S. mansoni - P. falciparum co-infections was $22.6 \%(95 \% \mathrm{Cl}, 15.3-31.3)$ and that of hookworm - P. falciparum co-infections $5.7 \%$ (95\%Cl, 2.6-12.8). Prevalence of co-infection of P. falciparum, S. mansoni and hookworm was $2.8 \%(95 \% \mathrm{Cl}, 1.15-4.4)$.

Conclusion: Multiple parasitic infections are common among schoolchildren in rural northwest Tanzania. These findings can be used for the design and implementation of sound intervention strategies to mitigate morbidity and co-morbidity.
\end{abstract}

\section{Background}

Parasitic infections present a major cause of disease and morbidity in Africa [1]. Among these diseases, Plasmodium falciparum inflicts the largest burden [2,3]. It is estimated that $40 \%$ of the world's population is at risk of malaria, and about $90 \%$ of the infected populations with malaria live in sub-Saharan Africa [4]. In Tanzania, over

\footnotetext{
* Correspondence: humphreymazigo@gmail.com

1 Weill-Bugando University College of Health Sciences, P.O. Box 1464, Mwanza, Tanzania

Full list of author information is available at the end of the article
}

95\% of the 38.7 million people are at risk for malaria; the disease contributes to $39 \%-48 \%$ of all outpatients [5].

Schistosomiasis is endemic in 76 countries worldwide and besides malaria is the second important parasitic disease for public health [6,7]. Of the 662 million people infected worldwide, $85 \%$ are from Africa [8]. In Tanzania, schistosomiasis is highly endemic and its prevalence varies from one region to another, with a prevalence of up to $80 \%$ in highly endemic areas [9].

The World Health Organization estimates that more than one billion people are chronically infected with soil- 
transmitted helminths [10]. Hookworms are estimated to affect 1300 million people [11].

Due to the fact that $P$. falciparum malaria and helminth infections are endemic throughout Tanzania, the affected populations often endure infections with a number of different species [12], and individuals are commonly coinfected with combinations of helminths and malaria parasites [13]. Such infections may have considerable health consequences, leading to more severe clinical symptoms and pathology than for infection with single parasite species. Interaction of malaria and helminth infections increase the severity of anaemia and organomegaly observed in schoolchildren and thus may potentially create a great challenge for disease control in the tropics. There is also evidence that co-infection with multiple parasites may alter the immune responses [14].

Overlap of schistosomes, soil-transmitted helminth and $P$. falciparum malaria depends on the conditions that favour multiple parasitic species survival and transmission [15]. These conditions include poverty, environmental contamination, water bodies and lack of effective preventive measures [15]. Polyparasitism of $P$. falciparum malaria, schistosomiasis and soil-transmitted helminth have been reported from various epidemiological settings in Africa [12,16,17], yet most parasitic diseases are still studied individually and data on prevalence, morbidity and mortality associated with multiple parasitic infections in Tanzania are limited.

This study was therefore conducted to determine the prevalence of P. falciparum malaria, S. mansoni and soiltransmitted helminth, and co-infections, among schoolchildren living in villages surrounding the Lake Victoria shore. Understanding the extent of polyparasitism in high-risk groups will serve as a guide in developing sound interventions strategies to reduce the burden of these diseases and co-morbidity.

\section{Materials and methods Study area and population}

Nyamatongo ward is located in Sengerema district in the Mwanza region, northwest Tanzania. The ward is located on the eastern side of the district and boarders Lake Victoria to the east. It has a population of about 21,000 . The study area is located at $1140 \mathrm{~m}$ altitude above sea level, and the inland area is covered by seasonal rivers and stream flowing down to the lake. The area is characterized by a tropical climate, with an average annual temperature of $26.5^{\circ} \mathrm{C}$, and experiences long rainy seasons between January and May. Annual average rainfall is 1065 $\mathrm{mm}$. The majority of inhabitants are involved in rural subsistence farming, fishing and livestock keeping.

The study was carried out between March - May 2009 among 400 schoolchildren from four primary schools, located $500 \mathrm{~m}-1500 \mathrm{~m}$ from the shore of Lake Victoria in
Sengerema district, northwest Tanzania. The inclusion criteria for the study were: (1) children aged 8-16 years; (2) parents or guardians gave written informed consent; (3) in addition to the written consent from caretakers, children also were supposed to agree and provide informed assent; (4) children lived in the study area.

\section{Study design}

A cross-sectional study was undertaken to determine the prevalence of $P$. falciparum malaria, S. mansoni and soiltransmitted helminth and any co-infections of $P$. falciparum, and intestinal helminths among schoolchildren. A two-step random sampling method was used to select children participating in the study. First, four schools of Nyamatongo ward were selected randomly. Second, using the class attendance registers, each child was given a number. Selection of the study participants was achieved by using tables of random numbers. Demographic data including age, gender and school/village where participants studied/lived were recorded by a structured questionnaire.

\section{Parasitological examination of S. mansoni and soil- transmitted helminths}

The day before parasitological screening commenced, schoolchildren were issued with plastic containers and instructed by a research team (HDM and NJSL) on how to collect a portion of their morning stool samples the next day. Stool containers were then collected at the school and labeled with identification numbers. These samples were brought to the field laboratory on the same day, and duplicate Kato-Katz cellophane thick smears was prepared from each specimen $[18,19]$. As a quality control measure, $10 \%$ of randomly selected smears were reexamined by a third experienced parasitologist who was blinded of the previous results. The mean number of eggs from each Kato Katz thick smear were multiplied by 24 in order to express infection intensities as the number of eggs per gram of faeces [18].

\section{Parasitological examination of malaria parasites}

A finger prick blood sample was collected after cleaning the finger surface using a sterile cotton wool soaked in methylated spirit. Two thick and one thin smears were prepared and stained with 10\% Giemsa (Sigma, Aldrich, Nairobi) in phosphate buffer [18]. Species specific and parasite densities were estimated under a light microscope at high magnification by counting the number of parasites per 200 white blood cells (WBC). If $<10$ parasites were found the reading was continued up to 500 WBC. The presence of either ring forms or gametocytes was conclusive diagnosis of $P$. falciparum. The counts of $P$. falciparum were converted to the number of parasite per $\mu \mathrm{l}$ of blood, assuming as standard a WBC count of $8000 / \mu \mathrm{l}[20]$. 


\section{Treatment}

Children found positive for hookworm and S. mansoni infections were treated with mebendazole $500 \mathrm{mg}$ and praziquantel $40 \mathrm{mg} / \mathrm{kg}$ [21]. Sweet potatoes and porridge were given before tablets in order to reduce the nauseating effects of praziquantel. Children positive for malaria parasites and body temperature above $37^{\circ} \mathrm{C}$ were treated with combination therapy of lumefantrine and artemether in collaboration with nearby health centers within the village.

\section{Ethical considerations}

The study was approved by the Institutional Review Board (Research and Publication Committee, certificate no. BREC/001/03/2009) of the Weill-Bugando University College Health Sciences and Bugando Medical Centre, Mwanza, Tanzania.

Prior to conducting the study, meetings were held with parents or guardians, teachers and community leaders to explain the aims and procedures to be used to collect data. Informed written consents were obtained from children's parents or guardians and in addition assent was subsequently obtained from children.

\section{Data analysis}

Data were entered into Microsoft Excel 2003 spreadsheets (Microsoft Corp., Redmond, WA, USA), checked for entry errors and analysed using SPSS for Windows version 11.5 (SPSS Inc., Chicago, IL, USA). Intensity of helminth infection was expressed as arithmetic mean from two Kato Katz thick smears [18]. Infection intensity of $S$. mansoni was classified into four groups according to WHO criteria: (1) light infection (1-100 eggs/g faeces (epg), (2) moderate infections (101-400 epg), (3) heavy infections (401-1000 epg) and (4) very heavy infections (> 1000 epg). For hookworms, infections were classified as follows: (1) light < 1000 epg; (2) moderate infection (1000-3999 epg) and (3) heavy infection (> $4000 \mathrm{epg}$ ) [20].

$P$. falciparum was specified on the basis of Giemsa stained blood smear examination, and infection intensities were classified into four groups: 1-50, 51-500, 5015000 and $>5000$ parasites $/ \mu$ l of blood [22].

The prevalence of single and multiple species of parasites were assessed and classified by gender and three age groups ( $\leq 10,11$ - 13 and $14-16$ years). Chi-squared $\left(\mathrm{X}^{2}\right)$ test was used to assess whether single and double or triple parasitic infections were associated with sex and age. Logistic regression analysis was applied to investigate whether gender and age were significantly associated with S. mansoni, P. falciparum and hookworms. A model of with $S$. mansoni infected children defined as cases incorporated age and sex. The adjusted odds ratios, including 95\% confidence interval and $P$-values were calculated. Similar procedures were repeated for hookworm and $P$. falciparum infections.

\section{Results}

A total of 400 schoolchildren aged 8-16 years were included. The age and sex distribution of study participants is shown in Table 1.

In total, $218 / 400$ (54.5\%, 95\% CI: 49.6-59.4) harboured at least one parasitic infection and 66/400 (16.5\%, 95\%CI 12.9-20.1) had none of the investigated parasitic infections.

The prevalence of S. mansoni was $64.3 \%$ (95\% CI: 59.668.9) with no significant difference among males and females (Table 2). The majority of the children infected with S. mansoni (35.4\%, 95\%CI: 30.7-40.1) had light infection (1-100 epg).

The overall hookworm prevalence was $38.5 \%$ (95\% CI: 33.2-42.8) with no significant differences between males and females (Table 2). Interestingly, prevalence of hookworms was observed to increase with age reaching maximum at $44.8 \%$ (95\% CI: 40-49.8) in the $14-16$ years age groups. About 32\% (95\% CI: 27.2-36.3) of the children had light hookworm infections with only $1 \%$ of the children harbouring heavy infections. Infections with other intestinal helminths such as T. trichiura or $A$. lumbricoides were not detected. Table 2 displays the overall prevalences and prevalences stratified by sex of the parasitic diseases identified in the study population.

Logistic regression analysis revealed significant associations between $S$. mansoni and hookworm infections with the age group (14-16 years), S. mansoni (adjusted $\mathrm{OR}=0.47, P<0.05,95 \% \mathrm{CI}: 0.25-0.87)$ and hookworm infection (adjusted OR $=1.85, P<0.002$, 95\% CI: 1.00 3.4 ), as compared to the $\geq 10$ year age group. Infection with $S$. mansoni (adjusted OR $=0.84,95 \% \mathrm{CI}$ : 0.55-1.26, $P$ $=0.41$ ) as well as with hookworms (adjusted OR $=0.98$, 95\% CI: 0.65-1.46, P = 0.92) was independent of gender.

Table 1: Study population in Nyamatongo ward, stratified by age and sex.

\begin{tabular}{|c|c|c|c|c|c|}
\hline Age (years) & Males & $\%$ & Females & $\%$ & Total \\
\hline$\leq 10$ & 33 & 16.8 & 50 & 24.5 & 83 \\
\hline $11-13$ & 104 & 53.1 & 106 & 52 & 210 \\
\hline $14-16$ & 59 & 30.1 & 48 & 23.5 & 107 \\
\hline Total & 196 & 100 & 204 & 100 & 400 \\
\hline
\end{tabular}


Table 2: Overall prevalence of parasitic diseases investigated, stratified by sex, among 400 schoolchildren in Nyamatongo ward, northwest Tanzania.

\begin{tabular}{|c|c|c|c|c|c|}
\hline & \multicolumn{5}{|c|}{ Prevalence of infection (\%) } \\
\hline & Overall N (\%) & $\begin{array}{c}95 \% \text { confidence } \\
\text { interval }\end{array}$ & $\begin{array}{c}\text { Females }(n=204) \\
N(\%)\end{array}$ & $\begin{array}{c}\text { Males }(n=196) \\
N(\%)\end{array}$ & $\begin{array}{c}\text { P-value } \\
\text { (males vs. females) }\end{array}$ \\
\hline \multicolumn{6}{|l|}{ Schistosomes } \\
\hline \multirow[t]{2}{*}{ Schistosoma mansoni } & 257 & $59.9-68.8$ & 135 & 122 & $P=0.31$ \\
\hline & $(64.3 \%)$ & & $(66.18 \%)$ & $(62.24 \%)$ & \\
\hline \multicolumn{6}{|l|}{$\begin{array}{l}\text { Soil-transmitted } \\
\text { helminths }\end{array}$} \\
\hline \multirow[t]{2}{*}{ Hookworm } & 152 & $33.7-42.8$ & $78(38.23 \%)$ & $74(37.8 \%)$ & $P=0.70$ \\
\hline & $(38.5 \%)$ & & & & \\
\hline \multicolumn{6}{|l|}{ Plasmodia } \\
\hline $\begin{array}{l}\text { Plasmodium } \\
\text { falciparum }\end{array}$ & $54(13.5 \%)$ & $10.2-16.9$ & $34(16.7 \%)$ & $20(10.2 \%)$ & $P=0.26$ \\
\hline Plasmodium ovale & $3(0.8 \%)$ & $0-10.9$ & $2(0.98 \%)$ & $1(0.51 \%)$ & \\
\hline $\begin{array}{l}\text { At least one } \\
\text { parasitic }\end{array}$ & 218 & $46.6-59.4$ & 110 & 108 & $P=0.39$ \\
\hline infection & $(54.5 \%)$ & & $(53.92 \%)$ & $(55.10 \%)$ & \\
\hline $\begin{array}{l}\text { Two or more } \\
\text { parasitic }\end{array}$ & $116(29 \%)$ & $24.6-33.4$ & $61(29.90 \%)$ & $55(47.41 \%)$ & \\
\hline infections & & & & & \\
\hline
\end{tabular}

Out of the 400 children tested for malaria parasites, 57 (14.3\%, 95\% CI: 10.8-17.7) were positive, with a prevalence of $P$. falciparum of $13.5 \%$ (Table 2). Three children $(0.8 \%, 3 / 400)$ were found to harbour $P$. ovale. None of the children harboured $P$. vivax or $P$. malariae. Malaria prevalence was highest in children aged $11-13$ years at $15.3 \%$ ( $\mathrm{n}=30$; 95\% CI: 11.7-18.7) and females had higher prevalence of asymptomatic malaria (16.6\%) (Table 3). About $65 \%$ of the children with $P$. falciparum infection had asymptomatic parasitaemia with 501-5000 parasites/ $\mu \mathrm{L}$ of blood (Table 3). However, no significant association was observed between age groups and $P$. falciparum infections $(P=0.73)$. Co-infection with more than one parasite species was common. The overall prevalence of at least two parasite species in study participants was 26.5\% ( $\mathrm{n}=106)$, 95\% CI, 22.2-30.8) (Table 2). About 69\% (73/106, 95\% CI: 64.4-73.4) of the children with dual infections were co-infected with hookworms and S. mansoni (Table 4). Other dual infections observed were between S. mansoni + P. falciparum (22.6\%, 24/106), hookworm $+P$. falciparum $(5.7 \%, 6 / 106)$. The prevalence of dual infections did not differ significantly by gender $(P$ $=0.068$ ). The age group 14-16 years exhibited high prevalence of dual infection (Table 4). Triple infections were

Table 3: Infection intensity of $P$. falciparum infections, stratified by sex and age $(n=397$, children infected with $P$. ovale were excluded).

1-50 n (\%) $\quad 51-500$ n (\%) $\quad 501-5000$ n (\%) $\quad>5000$ n (\%) $\quad$ P-value (males

\begin{tabular}{|c|c|c|c|c|c|}
\hline \multicolumn{6}{|l|}{ Sex } \\
\hline Male & 0 & $5(25 \%)$ & $13(65 \%)$ & 2 (10\%) & \\
\hline Female & 1 (2.94\%) & $10(29.41 \%)$ & 22 (64.71\%) & 1 (2.94\%) & $P=0.26$ \\
\hline \multicolumn{6}{|c|}{ Age (years) } \\
\hline$\leq 10$ & 0 & $2(22.22 \%$ & 7 (77.78\%) & 0 & \\
\hline $11-13$ & $1(3.13 \%)$ & 7 (21.88\%) & 22 (68.75\%) & $2(6.25 \%)$ & \\
\hline $14-16$ & 0 & $6(46.15 \%)$ & $6(46.15 \%)$ & 1 (7.69\%) & $P=0.73$ \\
\hline Total & 1 & 15 & 35 & 3 & \\
\hline
\end{tabular}


only observed in $2.8 \%$ ( $\mathrm{n}=11 / 400$; $95 \% \mathrm{CI}, 2.3-3.2)$ of the samples examined and these were for S. mansoni + hookworm $+P$. falciparum. Triple infections were most common in children in the age group 11-13 years and accounted for $72.7 \%$ of the cases $(n=8 / 11)$. Female children had the highest prevalence of triple infections $(64 \%$, 7/11).

\section{Discussion}

The findings from the current study confirm that Nyamatongo ward in northwest Tanzania is highly endemic for intestinal schistosomiasis and hookworm infections. $S$. mansoni was the most prevalent parasitic disease identified with almost $2 / 3$ of the schoolchildren infected. Prevalence of malaria was relatively low. Parasitic coinfections were common. Ascariasis and trichuriasis were absent.

Earlier studies conducted on other localities within the lake basin showed that both schistosomiasis and hookworm infections are common in the area $[9,23]$. However, prevalences in earlier studies were much lower $(10.9 \%-S$. mansoni) than in the present study probably due to focal exposure to $S$. mansoni by the population living in endemic areas as reported previously [24,25]. Infection intensities for $S$. mansoni in children were light to moderate, and only $7.5 \%$ of the children had heavy infections. These findings support previous observations that only few individuals in an endemic community excrete large numbers of eggs and that $S$. mansoni infections starts at early ages [26]. In the current study, children $<13$ years recorded highest infection rates with $S$. mansoni. Similar observations have been made for other areas [27]. On the other hand, the prevalence of S. mansoni was observed to decrease with increase in age of the children, which has also been reported in previous reports from Cote d'Ivoire
[27]. The decrease in prevalence of $S$. mansoni appears to coincide with the onset of puberty [25]. The prevalence of hookworm infections observed in the current study area (38\%) was similar to Magu district (37\%) within northwest Tanzania [9] but slightly lower than reported from Western Kenya (42.5\%) [25] and Brazil [28].

Our data confirm that among soil-transmitted helminths, hookworm infection is the major public health problem within the Lake basin $[9,25]$. A positive association between older age group (14-16 years) and hookworm infection was observed. A similar observation was made in locality in rural Côte d'Ivoire [27]. Hookworms were more widespread as compared to other soil-transmitted helminth infections, namely $A$. lumbricoides and T. trichiura, which occur in various ecological settings of sub-Saharan African [29]. Interestingly, earlier studies in Magu district, northwest Tanzania, reported a prevalence of ascariasis of $<1 \%$ [9] and a report by Handzel et al. [25] in Kenya's Nyanza province reported a prevalence of $22.9 \%$ and $17.9 \%$ for A. lumbricoides and T. trichuris. Variability in endemicity or prevalence of these infections, low sensitivity of the diagnostic method, the use of single stool sample, environmental contamination and inability of the helminth eggs to withstand high temperature could partly explain the observed difference. The prevalence of $P$. falciparum malaria in Nyamatongo ward was relatively low (13.5\%) in spite of the locality being within a malaria holoendemic area [30]. Our findings confirm other studies conducted in Tanzania [31,32], but are different from data among primary schoolchildren in holoendemic areas of Cameroon [33].

This difference could be attributed to low malaria prevalence in the study area or high mosquito net coverage which was not assessed in the present study. A particular concern is the high occurrence of parasitic co-infections,

Table 4: Prevalence of double and triple parasitic infections, stratified by age and sex among 400 primary schoolchildren in the Nyamatongo ward.

\begin{tabular}{|c|c|c|c|c|c|}
\hline \multirow[b]{2}{*}{ Variable } & \multicolumn{4}{|c|}{ Prevalence of double and triple infections } & \multirow[b]{2}{*}{$\begin{array}{c}\text { P. falciparum + } \\
\text { S. mansoni + } \\
\text { hookworm }\end{array}$} \\
\hline & & $\begin{array}{l}\text { S. mansoni + } \\
\text { P. falciparum }\end{array}$ & $\begin{array}{c}\text { S. mansoni + } \\
\text { Hookworm }\end{array}$ & $\begin{array}{c}\text { P. falciparum + } \\
\text { hookworm }\end{array}$ & \\
\hline Sex & $\mathrm{N}$ & $\mathrm{N}(\%)$ & $\mathrm{N}(\%)$ & $\mathrm{N}(\%)$ & $\mathrm{N}(\%)$ \\
\hline Female & 204 & $14(6.9 \%)$ & $33(16.2 \%)$ & $5(2.5 \%)$ & $7(3.4 \%)$ \\
\hline Male & 196 & $10(5.1 \%)$ & $40(20.4 \%)$ & $1(0.5 \%)$ & $4(2.1 \%)$ \\
\hline \multicolumn{6}{|l|}{ Age (years) } \\
\hline$\leq 10$ & 83 & $4(4.8 \%)$ & $16(19.3 \%)$ & 0 & $2(2.4 \%)$ \\
\hline $11-13$ & 210 & $14(6.7 \%)$ & $33(15.7 \%)$ & $3(1.4 \%)$ & $8(3.8 \%)$ \\
\hline $14-16$ & 107 & $24(17.1 \%)$ & 73 (57.4\%) & $6(1.42 \%)$ & $1(0.9 \%)$ \\
\hline All age groups & 400 & 42 & 122 & 9 & 11 \\
\hline
\end{tabular}


with concomitant infections of S. mansoni and hookworms being the most common. Co-infections of helminth and $P$. falciparum infections also have clinical importance [34]. Previous studies have clearly documented the relationship between intestinal helminth infections, polyparasitism and cognitive functions, growth and malnutrition among school children [35,36]. Hookworm anemia may be exacerbated by infection with other parasites [29]. Children with multiple parasitic infections especially those with heavy infections intensity tend to experience more severe cognitive outcomes and other health problems such as malnutrition than children with only one helminth infection [36,37]. Studies suggest that co-infections of $P$. falciparum with hookworms or schistosomes tend to exacerbate hepato-splenic, anaemia and malnutrition morbidities among school children [38].

Co-infections of $S$. mansoni and hookworm could partly be attributed to the co-endemicity of the two species in the study area and poor sanitations [28,39,40]. This observation is similar to previously reports from Brazil [28] Côte d'Ivoire [27] and China [40]. The polyparasitism of S. mansoni and P. falciparum observed in the present study have also been observed previously from Senegal [41] and Zimbabwe [42] where prevalence of $P$. falciparum among schoolchildren were high in those infected with $S$. mansoni. One reason for this observation could be the availability of breeding sites for the intermediate host (fresh water snail) and malaria vectors (Anopheles mosquitoes) in the study area. Furthermore, heavy intensities of $S$. mansoni infection did not correlate with having heavy intensities of $P$. falciparum. The findings of our study were similar to a study from Uganda [38].

Hookworm and $P$. falciparum co-infections were more common in our study than reports from Cameroon (0.2\%) [33] but lower than in Zimbabwe (12.6\%) and Western Kenya (41.5\%) [25,43]. Difference in geographical variations in exposure and endemicity could be one of the reasons for these differences. However, in this study, $P$. falciparum infection showed no significant association with hookworms.

Similar to our results, triple infections of $P$. falciparum, hookworm and $S$. mansoni have been reported in studies from Côte d'Ivore, Cameroon and Zimbabwe [39,33,42]. These studies conducted throughout Africa and China indicate clearly that most parasitic infections do not occur singly but as co-infections [28,29,39,40]. Although both malaria and helminths have distinct means of transmission patterns, a variety of environmental and host factors may influence their epidemiological and geographical patterns of infections and diseases [34]. In conclusion, this study revealed that $S$. mansoni, hookworm and P. falciparum are prevalent among schoolchildren in the study area. The findings of the present study, supports the need for initiatives to implement a new framework for an integrated approach in disease management. We also recommend longitudinal studies to identify the associations between parasites and associated morbidity.

\section{Competing interests}

The authors declare that they have no competing interests.

\section{Authors' contributions}

HDM, GMM, RW and NJSL designed the study and participated in data collection. JS and AK assisted in data collection. JH, HDM, SEM, LML, AMM and EJK analysed the data. HDM and SEM wrote the first draft of the manuscript. All authors contributed to the manuscript and approved its final version.

\section{Acknowledgements}

HDM received funds from Weill-Bugando University College of Health Sciences, Mwanza, Tanzania for postgraduate training in Msc Medical Parasitology \& Entomology (ITROMID-KEMRI+ JKUAT). JH is research fellow from the Conselho Nacional de Desenvolvimento Científico e Tecnológico (CNPq/Brazil). We thank the school children and their teachers of Irunda, Nyarwambu, Kamanga and Karumo primary schools and parents for their cooperation during the Study. We are grateful to Mr. John Igogote and Mr. James Anicetus Kubeja from National Medical Research Institute, Mwanza Centre for their technical assistance.

\section{Author Details}

1Weill-Bugando University College of Health Sciences, P.O. Box 1464, Mwanza, Tanzania, 2Department of Zoology, Jomo Kenyatta University of Agriculture and Technology, P.O. Box 62000-00200, Nairobi, Kenya, ${ }^{3}$ National Institute for Medical Research, Mwanza Center, P.O. Box 1462 Mwanza, Tanzania, ${ }^{5}$ Sokoine University of Agriculture, Pest Management Center, P.O. Box 3010 Morogoro, Tanzania, 5 Tropical Pesticides Research Institute, Division of Livestock and Human Disease vector control, P.O. Box 3024, Arusha, Tanzania, ${ }^{6}$ Anton Breinl Centre for Tropical Medicine and Public Health; School of Public Health, Tropical Medicine and Rehabilitation Sciences, James Cook University, Townsville, Australia and IInstitute of Tropical Medicine and Infectious Diseases, Jomo Kenyatta University of Agriculture and Technology, P.O. Box 62000-00200, Nairobi, Kenya

Received: 23 April 2010 Accepted: 19 May 2010 Published: 19 May 2010

\section{References}

1. World Health Organization: Schistosomiasis and soil-transmitted infections. 54th World Health Assembly, agenda item 13.3 resolution WHA 54.19

2. World Health Organization: Reducing risks, promoting healthy life. The World Health Report 2002. In Burden of disease in DAILYs by cause, sex and mortality stratums in WHO regions, estimates for 2001 Geneva, World Health Organization; 2002:192.

3. Snow RW, Guerra CA, Noor AM, Myint HY, Hay SI: The global distribution of clinical episodes of Plasmodium falciparum malaria. Nature 2005, 434:214-217.

4. Greenwood B, Mutabingwa T: Malaria in 2002. Nature 2002, 415:670-72

5. Ministry of Health: Annual Health Statistics Abstract. 2002 Ministry of Health and Social Welfare, Dar es Salaam, United Republic of Tanzania

6. Tropical Disease Research: Schistosomiasis diseases information. Special Programme for Research and Training in Tropical Diseases (TDR) [http:// apps.who.int/tdr/svc/diseases/schistosomiasis].

7. Crompton DWT, Montressor A, Neisheim MC, Savioli L: Controlling disease due to helminth infection. World Health Organization, Geneva; 2003

8. Chitsulo L, Engels D, Montresor A, Savioli L: The global status of schistosomiasis and its control. Acta Trop 2000, 77:41-51.

9. Lwambo NJS, Siza JE, Brooker S, Bundy DAP, Guyatt H: Patterns of concurrent hookworm infection and schistosomiasis in schoolchildren in Tanzania. Trans R Soc Trop Med Hyg 1999, 93:497-502.

10. Montresor A, Crompton DWT, Hall A, Bundy DAP: Guidelines for the evaluation of soil-transmitted helminthiasis and schistosomiasis at community level (WHO/CTD/SIP/98.1). Geneva: World Health Organization; 1998. 
11. Brooker S, Clements AC, Bundy DA: Global epidemiology, ecology and control of soil-transmitted helminth infection. Adv Parasitol 2006, 62:221-261.

12. Petney TN, Andrews RH: Multiparasite communities in animals and humans: frequency, structure and pathogenic significance. Int $J$ Parasitol 1998, 28:377-93.

13. Booth M, Bundy DA, Albanico M, Chwaya HM, Alawi KS, Savioli L: Association among multiple geohelminth species infections in school children from Pemba Island. Parasitol 1998, 116:85-93.

14. Nacher M, Singhasivanon P, Silachamroon U, Treeprasertsu S, Krudsood S, Gay F, Mazier D, Looareesuwan S: Association of helminth infections with increased gametocyte carriage during mild falciparum malaria in Thailand. Am J Trop Med Hyg 2001, 65:644-647.

15. Booth $\mathrm{M}$ : The role of residential location in apparent helminth and malaria infection. Trends Parasitol 2006, 22:359-62.

16. World Health Organization: Prevention and control of schistosomiasis and soil-transmitted helminthiasis: first report of the joint WHO expert committees. WHO Technical Report Series 2002 No. 912:1-57.

17. Buck AA, Anderson RI, MacRae AA: Epidemiology of poly-parasitism I. Occurrence, frequency and distribution of multiple infections in rural communities in Chad, Peru, Afghanistan and Zaire. Trop Med Parasitol 1978, 29:61-70.

18. World Health Organization: Basic Laboratory Methods in Medical Parasitology. World Health Organization, Geneva; 1993.

19. Martin LK, Beaver PC: Evaluation of Kato thick-smear technique for quantitative diagnosis of helminth infections. Am J Trop Med Hyg 1968, 17:382-391

20. Cheesbrough M: District Laboratory Practice in Tropical Countries, Part I. Tropical Health Technology/Cambridge University Press, Cambridge 1968:197-199

21. World Health Organization: Guidelines for evaluations of soiltransmitted helminthiasis and schistosomiasis at community level. WHO/CTD/SIP/98.1.

22. Stoltzfus RJ, Albonico M, Chwaya HM, Savioli L, Tielsch J, Schulze K, Yip R Hemoquant determination of hookworm-related blood loss and its role in iron deficiency in African children. Am J Trop Med Hyg 1996, 55:399-404

23. Ajanga A, Lwambo NJS, Blair L, Nyandindi U, Fenwick A, Brooker S: Schistosoma mansoni in Pregnancy and associations with anaemia in northwest, Tanzania. Trans R Soc Trop MedHyg 2006, 100:59-63.

24. Booth M, Vennervald BJ, Kenty L, Butterworth AE, Kariuki HC, Kadzo H, Ireri E, Amanganga C, Kimani G, Mwatha JK, Otedo A, Ouma JH, Muchiri E, Dunne DW: Microgeographical variation in exposure to Schistosoma mansoni and malaria and exacerbation of splenomegaly in Kenyan school-aged children. BMC Infect Dis 2004, 4:13.

25. Handzel T, Karanja DM, Addiss DG, Hightower AW, Rosen DH, Colley DG, Andove J, Slutsker L, Evansecor W: Geographic distribution of schistosomiasis and soil-transmitted helminths in Western Kenya: Implication for anthelminthic mass treatment. Am J Trop Med Hyg 2003, 69:318-323

26. Butterworth AE, Sturrock RF, Ouma JH, Mbugua GG, Fulford AJC, Kariuki $H C$, Koesh D: Comparison of different chemotherapy strategies against Schistosoma mansoni in Machako's District, Kenya. Effects on human infections and morbidity. Parasitol 1991, 103:339-355.

27. Keiser J, N'Goran EK, Singer BH, Lengeler C, Tanner M, Utzinger J: Association between Schistosoma mansoni and hookworm infections among schoolchildren in Côte d'Ivoire. Acta Trop 2002, 84:31-41.

28. Fleming FM, Brooker S, Geiger SM, Caldas IR, Oliveira RC, Hotez PJ, Bethony $\mathrm{M}$ : Synergistic associations between hookworm and other helminths species in a rural community in Brazil. Trop Med Int Health 2006, 11:56-64.

29. Brooker S, Clements ACA, Hotez PJ, Hay SI, Tatem AJ, Bundy DAP, Snow RW: The co-distribution of Plasmodium falciparum and hookworm among African schoolchildren. Malaria J 2006, 5:99.

30. Mboera LEG, Mlozi MRS, Senkoro KP, Rwegoshora RT, Rumisha SF, Mayala BK, Shayo EH, Senkondo E, Mutayoba B, Mwingira V, Maerere A: Malaria and Agriculture in Tanzania: Impact of Land Use and Agricultural Practices on Malaria Burden in Mvomero District. National Institute for Medical Research, Dar es Salaam, Tanzania; 2007.

31. Mboera LEG, Kamugisha M, Rumisha SF, Kisinza WN, Senkoro KP, Kitua A: Malaria and mosquito net utilisation among schoolchildren in villages with or without healthcare facilities at different altitudes in Iringa District, Tanzania. Afr J Health Sc 2008, 8:114-118.

32. Mboera LEG, Kadete L, Nyange A, Molteni F: Urban malaria in Dodoma and Iringa, Tanzania. Tanz Health Res Bul 2006, 8:115-118,

33. Nkuo-Akenji TK, Chi CC, Cho JF, Ndamukong KJ, Sumbele I: Malaria and helminths co-infection in children living in a malaria endemic setting of Mount Cameroon and predictors of anaemia. J Parasitol 2006, 92:1191-1195.

34. Mwangi T, Bethony J, Brooker S: Malaria and helminths interactions in humans: an epidemiological viewpoint. Ann Med Parasitol 2007 100:551-570.

35. Partnership for Child Development: Heavy schistosomiasis associated with poor short term memory and slower reaction times in Tanzanian schoolchildren. Trop Med Int Health 2002, 7:104-117.

36. Jardiam-Batelho A, Raff S, de Avilla Rodrigues R, Hoffman HJ, Diemert DJ, Correa-Oliveira R, Bethony JM, Gazzinelli MF: Hookworm, Ascaris lumbricoides infections and polyparasitism associated with poor cognitive performance in Brazilian schoolchildren. Trop Med Int Health 2008, 13(8):994-1004.

37. Sakti H, Nokes C, Hertanto WS, Hendratno S, Hall A, Bundy DAP, Satoto : Evidence for an association between hookworm infection and cognitive function in Indonesian school children. Trop Med Int Health 1999, 4:322-334

38. Shapiro AE, Tukulembwa EM, Kasten J, Clarke SE, Magnussen P, Olsen A, Kabeteraine NB, Ndyomugyenyi R, Brooker S: Epidemiology of helminths infections and their relationship to clinical malaria in south west Uganda. Trans R Soc Trop Med Hyg 2005, 99:18-24.

39. Raso G, Lugibuhl A, Adjoua CA, Tian-Bi NT, Silue KD, Matthys B, Vounatsou P, Dumas ME, Holmes E, Singer BH, Tanner M, N'goran KE, Utzinger J: Multiple parasite infections and their relationship to self-reported morbidity in a community of rural Cote d'Ivoire. Int J Epidemio/ 2004 33:1092-1102

40. Steinmann $P$, Du ZW, Wang LB, Wang XZ, Jiang JY, Li LH, Marti H, Zhou XN, Utzinger J: Extensive Multiparasitism in a Village of Yunnan Province, People's Republic of China, Revealed by a Suite of Diagnostic Methods. Am J Trop Med Hyg 2008, 78(5):760-769.

41. Sokhana C, Le Hesran JY, Mbaye PA, Akiana J, Camara P, Diop M, Ly A, Druilhe $P$ : Increase of malaria attacks among children presenting concomitant infection by Schistosoma mansoni in Senegal. Mal J 2004, 3:43.

42. Midzi N, Sangweme D, Zinyowera S, Mapingure MP, Brouwer KC, Munatsi A, Mutapi F, Mudzori J, Kumar N, Woelk G, Mduluza T: The burden of Polyparasitism among primary schoolchildren in rural and farming areas in Zimbabwe. Trans R Soc Trop Med Hyg 2008, 102:1039-1045.

43. Olsen A, Magnussen P, Ouma JH, Andreassen J, Friis H: The contribution of hookworm and other parasitic infections to haemoglobin and iron status among children and adults in Western Kenya. Trans R Soc Trop Med Hyg 1998, 92:643-649.

doi: 10.1186/1756-3305-3-44

Cite this article as: Mazigo et al., Co-infections with Plasmodium falciparum, Schistosoma mansoni and intestinal helminths among schoolchildren in endemic areas of northwestern Tanzania Parasites \& Vectors 2010, 3:44

\section{Submit your next manuscript to BioMed Centra and take full advantage of:}

- Convenient online submission

- Thorough peer review

- No space constraints or color figure charges

- Immediate publication on acceptance

- Inclusion in PubMed, CAS, Scopus and Google Scholar

- Research which is freely available for redistribution 